\title{
COVID-19 critical illness in Sweden: characteristics and outcomes at a national population level
}

Johan Mårtensson, * Lars Engerström, * Sten Walther, Jonathan Grip, Ritva Kiiski Berggren and Emma Larsson www.doi.org/10.51893/2020.4.oa3

Published on line first 7 December 2020

The global burden of coronavirus disease 2019 (COVID-19) has increased dramatically since the first case was identified in December 2019. Although most persons infected by the severe acute respiratory syndrome coronavirus 2 (SARSCoV-2) develop mild disease, $5-30 \%$ of patients admitted to hospital progress to severe COVID-19 requiring admission to an intensive care unit (ICU). ${ }^{1-5}$

In previous preliminary reports, between $30 \%$ and $80 \%$ of all ICU patients with COVID-19 died. 1,3,6-10 The highest mortality rates have been observed among older patients and among patients with multiple comorbidities, including hypertension and diabetes.2,8,11-13 To date, however, characteristics and outcomes of ICU patients have mainly been described in studies with short follow-up time or limited power to assess the impact of potential risk factors on clinical outcomes.

On 6 March 2020, the first patient with COVID-19 was admitted to an ICU in Sweden. In response to the reported outbreaks in China and Italy, ${ }^{1,2}$ mobilisation of personnel, equipment and facilities started mid-March, with a gradual increase of staffed ICU beds. The Swedish Intensive Care Registry (SIR) has been collecting individual patient data from all 83 ICUs in Sweden since 2001. In cooperation with the Public Health Agency of Sweden, mandatory surveillance data of a number of communicable diseases including COVID-19 are routinely reported.

In this population-based cohort study, we aimed to describe the clinical characteristics, process of care, and 30-day mortality of all critically ill patients with COVID-19 admitted to an ICU in Sweden. In addition, we aimed to assess the independent association between potential patient-related risk factors and mortality within 30 days of ICU admission.

\section{Methods}

This study was approved by the Swedish Ethics Review Authority (approval number 2020-01477). Data were extracted from SIR, which collects individual data from all Swedish ICUs and operates within the legal framework of the Swedish National Quality Registries. ${ }^{14}$ This framework does not require written informed consent from the

\begin{abstract}
Objective: During the coronavirus disease 2019 (COVID-19) pandemic, baseline demographics and comorbidities of patients with COVID-19 have been presented, but there are limited data on outcomes of severely ill patients. We aimed to examine the association between patient characteristics and 30-day mortality among patients with COVID-19 treated in the intensive care unit (ICU).
\end{abstract}

Design: Population-based cohort study.

Setting: ICUs in Sweden.

Participants: All consecutive patients with COVID-19 admitted to Swedish ICUs from 6 March to 5 April 2020.

Main outcome measures: The primary outcome was 30day mortality after ICU admission. Patient demographics, comorbidities and clinical characteristics were also retrieved.

Results: A total of 604 patients were included. The median age was 61 years (interquartile range [IQR], 52-70 years) and 458 patients $(76 \%)$ were males. The most common comorbidities were hypertension (35.9\%) and diabetes $(25.7 \%)$, whereas $36.4 \%$ of patients had no comorbidities. Median Simplified Acute Physiology Score (SAPS) 3 was 53 (IQR, 46-60). Of 573 patients with available respiratory support data, $487(85.0 \%)$ received invasive mechanical ventilation. Among 518 patients with available data, 117 $(22.6 \%)$ received renal replacement therapy. Median length of stay was 13 days (IQR, 6-20 days). Mortality at 30 days was $32.6 \%$. In the multivariable Cox regression model, age (hazard ratio [HR] 1.06; 95\% Cl, 1.04-1.07 per year), the presence of one or more comorbidities (HR, 1.80; 95\% $\mathrm{Cl}, 1.20-2.68)$, chronic obstructive pulmonary disease or asthma (HR, 1.68; 95\% Cl, 1.12-2.50), hypertension (HR, $1.41 ; 95 \% \mathrm{Cl}, 1.01-1.99$ ), and acute illness severity (SAPS 3 excluding age and comorbidity) (HR, 1.06; $95 \% \mathrm{Cl}, 1.04-$ 1.09) were associated with 30-day mortality.

Conclusions: This population-based cohort study presents 30-day mortality of 604 ICU patients with COVID-19. The higher mortality was explained by older age, the presence chronic illness, and acute illness severity.

Crit Care Resusc 2020; 22 (4): 312-320 


\section{ORIGINAL ARTICLES}

patients, but patients may withdraw their data from the registry at any time. Public health care, including intensive care, is tax-funded and available for all citizens in Sweden regardless of private health insurance.

\section{Setting and participants}

We identified all admissions in SIR with confirmed SARSCoV-2 infection by polymerase chain reaction (PCR) between 6 March and 5 April 2020. We excluded patients without data on follow-up and patients who tested positive for SARS-CoV-2 RNA with other reason for admission than COVID-19. Patients were followed from baseline until death or 26 May 2020, whichever came first. During the inclusion period, 65/83 Swedish ICUs admitted patients with COVID-19.

As of 5 April 2020, 7171 patients had tested positive for SARS-CoV-2 RNA and 690 deaths were registered due to COVID-19 in Sweden. ${ }^{15}$ During the study period, a total of 4332 patients with COVID-19 had been admitted to hospital. ${ }^{16}$

\section{Variables and definitions}

The SIR collects information on baseline patient characteristics, variables included in the Simplified Acute Physiology Score (SAPS) 3 model, and ICU treatment variables. Baseline characteristics were determined at the time of ICU admission. Physiological data were recorded within one hour before until one hour after ICU arrival. For each physiological variable, the most severe deviation within the specified time span was used. Survival was ascertained by linking SIR to the Swedish Population Register. The primary end point was survival 30 days after admission to ICU. Data were recorded in raw format and transferred electronically to SIR after local validation. The data were entered by intensive care doctors, nurses, or care administrators trained in registration. After central validation, incomplete or inconsistent (entries outside pre-specified limits) patient records were returned to the specific ICUs for correction before the data were accepted and added to the master database.

\section{Statistical analysis}

Categorical variables are presented as number (with percentage). Continuous variables are summarised as median with interquartile range (IQR). Data were analysed using STATA/SE 16 (StataCorp, College Station, TX, USA) and $R$ version 3.6.3 ( $R$ Foundation for Statistical Computing, Vienna, Austria). Time to death was displayed using the Kaplan-Meier methodology. Analyses of potential risk factors for 30-day mortality were performed using a univariable and multivariable Cox regression model. We considered the following variables for inclusion in the regression model: age, sex, comorbidities (no comorbidity, one or more comorbidities), hospital level (tertiary, county, local) and acute illness severity at admission (SAPS 3 excluding age and comorbidity components). In addition, a Cox regression model was also performed using the following comorbidities as separate covariates: chronic obstructive pulmonary disease (COPD) or asthma, chronic cardiac disease, diabetes, morbid obesity (body mass index $>40 \mathrm{~kg} / \mathrm{m}^{2}$ ) and hypertension. Variables with univariable significance at $P<0.05$ were carried forward to the multivariable models. Data were analysed as complete cases. A two-sided $P<0.05$ was considered statistically significant.

\section{Results}

\section{Patients}

From 6 March to 5 April 2020, a total of 633 ICU patients with confirmed SARS-CoV-2 infection were reported to SIR. We excluded 13 patients who were admitted without a primary diagnosis associated with COVID-19 and 16 patients without available outcome data. Therefore, we included 604 patients with laboratory-confirmed COVID-19 in the final analyses (Figure 1). Median number of admissions per site was 5.5 (IQR, 4-15; range, 1-82). Baseline characteristics are presented in Table 1. For the entire cohort, the median age was 61 years (IQR, 52-70 years), and 458 patients $(75.8 \%)$ were men. About one-quarter of the patients were admitted from the emergency department (ED). Median duration of symptoms before ICU admission was 9 days (IQR, 7-12 days). Most patients were admitted to tertiary $(36.9 \%)$ or county $(54.8 \%)$ hospitals. Overall, 220 patients (36.4\%) had no reported comorbidity at admission. The most common comorbidities were hypertension (35.9\%) and diabetes (25.7\%). Median SAPS 3 at admission was 53 (IQR, 46-60), corresponding to a median predicted
Figure 1. Flow chart of included patients

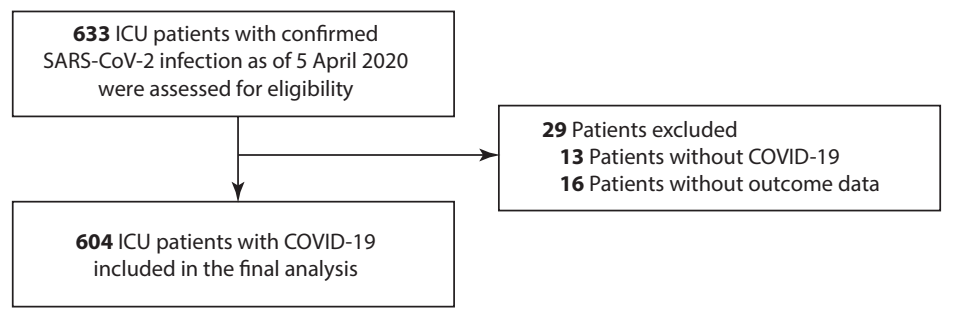

COVID-19 = coronavirus disease 2019; ICU = intensive care unit; SARS-CoV-2 = severe acute respiratory syndrome coronavirus 2 . 


\section{Table 1. Baseline characteristics among survivors and non-survivors}

\begin{tabular}{|c|c|c|c|}
\hline Characteristic & All patients & Survivors & Non-survivors \\
\hline Total number of patients & $604(100 \%)$ & $407(67.4 \%)$ & $197(32.6 \%)$ \\
\hline Median age (IQR), years) & $61(52-70)$ & $58(50-65)$ & $68(61-75)$ \\
\hline \multicolumn{4}{|l|}{ Age interval (years) } \\
\hline$<40$ & $46(7.6 \%)$ & $42(10.3 \%)$ & $4(2.0 \%)$ \\
\hline $40-49$ & $68(11.3 \%)$ & $59(14.5 \%)$ & $9(4.6 \%)$ \\
\hline $50-59$ & $157(26.0 \%)$ & $126(31.0 \%)$ & $31(15.7 \%)$ \\
\hline $60-69$ & $181(30 \%)$ & $119(29.2 \%)$ & $62(31.5 \%)$ \\
\hline $70-79$ & $130(21.5 \%)$ & $56(13.8 \%)$ & $74(37.6 \%)$ \\
\hline$\geq 80$ & $22(3.6 \%)$ & $5(1.2 \%)$ & $17(8.6 \%)$ \\
\hline Sex, male & $458(75.8 \%)$ & $306(75.2 \%)$ & $152(77.2 \%)$ \\
\hline $\begin{array}{l}\text { Location before ICU admission (number } \\
\text { of patients with data) }\end{array}$ & 583 & 391 & 192 \\
\hline Emergency department & $131(22.5 \%)$ & $68(17.4 \%)$ & $63(32.8 \%)$ \\
\hline Hospital ward & $452(77.5 \%)$ & $323(82.6 \%)$ & $129(67.2 \%)$ \\
\hline $\begin{array}{l}\text { Median time from symptom to ICU } \\
\text { admission (IQR), days }\end{array}$ & $9(7-12)$ & $10(7-12)$ & $9(7-11)$ \\
\hline \multicolumn{4}{|l|}{ Hospital level } \\
\hline Tertiary & $223(36.9 \%)$ & $170(41.8 \%)$ & $53(26.9 \%)$ \\
\hline County & $331(54.8 \%)$ & $204(50.1 \%)$ & $127(64.5 \%)$ \\
\hline Local & $50(8.3 \%)$ & $33(8.1 \%)$ & $17(8.6 \%)$ \\
\hline Days at hospital before ICU admission & 575 & 385 & 190 \\
\hline Median (IQR) & $1(0-3)$ & $1(0-3)$ & $1(0-3)$ \\
\hline Pregnancy & $3(0.5 \%)$ & $3(0.7 \%)$ & 0 \\
\hline \multicolumn{4}{|l|}{ Comorbidities } \\
\hline None & $220(36.4 \%)$ & $168(41.3 \%)$ & $52(26.4 \%)$ \\
\hline One or more & $384(63.6 \%)$ & $239(58.7 \%)$ & $145(73.6 \%)$ \\
\hline Chronic hypertension & $217(35.9 \%)$ & $130(31.9 \%)$ & $87(44.2 \%)$ \\
\hline Chronic cardiac disease & $60(9.9 \%)$ & $37(9.1 \%)$ & $23(11.7 \%)$ \\
\hline COPD or asthma & $97(16.1 \%)$ & $53(13.0 \%)$ & $44(22.3 \%)$ \\
\hline Immunodeficiency & $37(6.1 \%)$ & $22(5.4 \%)$ & $15(7.6 \%)$ \\
\hline Chronic liver disease & $5(0.8 \%)$ & $2(0.5 \%)$ & $3(1.5 \%)$ \\
\hline Chronic kidney disease & $23(3.8 \%)$ & $16(3.9 \%)$ & $7(3.6 \%)$ \\
\hline Diabetes & $155(25.7 \%)$ & $108(26.5 \%)$ & $47(23.9 \%)$ \\
\hline Neuromuscular disease & $6(1.0 \%)$ & $2(0.5 \%)$ & $4(2.0 \%)$ \\
\hline Morbid obesity* & $42(7.0 \%)$ & $28(6.9 \%)$ & $14(7.1 \%)$ \\
\hline Malignancy $^{\dagger}$ & $8 / 575(1.4 \%)$ & $2 / 385(0.5 \%)$ & $6 / 190(3.2 \%)$ \\
\hline Vasopressor on admission & $21 / 575(3.7 \%)$ & $11 / 385(2.9 \%)$ & $10 / 190(5.3 \%)$ \\
\hline Fever $^{\ddagger}$ & $\begin{array}{l}266 / 553 \\
(48.1 \%)\end{array}$ & $\begin{array}{l}187 / 367 \\
(51.0 \%)\end{array}$ & $79 / 186(42.5 \%)$ \\
\hline \multicolumn{4}{|l|}{ Glasgow Coma Scale score } \\
\hline Number of patients & 281 & 184 & 97 \\
\hline \multirow[t]{2}{*}{ Median (IQR) } & $15(14-15)$ & $15(15-15)$ & $15(14-15)$ \\
\hline & & & (continues) \\
\hline
\end{tabular}

risk of death of $22 \%$ (IQR, $12-36 \%)$. Mortality at 30 days was $32.6 \%$. Compared with survivors, non-survivors were older (68 [IQR, 61-75] v 58 [IQR, 50-65] years), were more likely to be admitted from the ED (32.8\% v 17.4\%) and were more likely to have one or more comorbidities (73.6\% v 58.7\%). In particular, hypertension and COPD or asthma were more common among the nonsurvivors. Median SAPS 3 was 51 (IQR, 45-56) in survivors compared with 59 (IQR, 52-64) in non-survivors.

\section{Process of care}

The process of care is presented in Table 2. Overall, $85.0 \%$ of patients received invasive mechanical ventilation for a median total duration of 282 hours (IQR, 177-444 hours) and $22.6 \%$ received renal replacement therapy. Median total length of ICU stay was 13 days (IQR, 6-20 days). At 30 days after admission, 50 patients were still in the ICU. Compared with survivors, nonsurvivors were more likely to receive invasive mechanical ventilation $(91.0 \% \quad v \quad 82.0 \%)$ and renal replacement therapy $(28.4 \% \vee 19.6 \%)$. A similar proportion of survivors and nonsurvivors received chloroquine phosphate before or during ICU care.

\section{Thirty-day mortality}

We observed an almost exponential relationship between age and crude mortality: less than 10\% observed mortality in patients younger than 40 years and close to $80 \%$ in patients 80 years or older (Figure 2). 
Table 1. Baseline characteristics among survivors and non-survivors (continued)

\begin{tabular}{|c|c|c|c|}
\hline Characteristic & All patients & Survivors & Non-survivors \\
\hline \multicolumn{4}{|l|}{ Systolic blood pressure } \\
\hline Number of patients & 549 & 365 & 184 \\
\hline Median (IQR), mmHg & $120(100-140)$ & $120(102-140)$ & $112(95-130)$ \\
\hline \multicolumn{4}{|l|}{ Heart rate } \\
\hline Number of patients & 555 & 370 & 185 \\
\hline Median (IQR), beats/min & 95 (83-109) & $95(81-106)$ & $95(85-110)$ \\
\hline \multicolumn{4}{|l|}{$\mathrm{PaO}_{2}$} \\
\hline Number of patients & 520 & 342 & 178 \\
\hline Median (IQR), mmHg & $70(59-83)$ & $70(60-83)$ & $69(56-83)$ \\
\hline \multicolumn{4}{|l|}{$\mathrm{FiO}_{2}$} \\
\hline Number of patients & 406 & 262 & 144 \\
\hline Median (IQR), \% & $70(56-85)$ & $70(55-80)$ & $73(60-90)$ \\
\hline \multicolumn{4}{|l|}{$\mathrm{PaO}_{2}: \mathrm{FiO}_{2}$ ratio } \\
\hline Number of patients & 402 & 260 & 141 \\
\hline Median (IQR) & $106(78-150)$ & $108(80-152)$ & $105(75-141)$ \\
\hline \multicolumn{4}{|l|}{ White blood cell count } \\
\hline Number of patients & 523 & 344 & 179 \\
\hline Median (IQR), $\times 10^{9} / \mathrm{L}$ & $8.0(6.1-10.4)$ & $8.0(6.2-10.3)$ & $8.1(5.8-10.8)$ \\
\hline \multicolumn{4}{|l|}{$\mathrm{pH}$} \\
\hline Number of patients & 538 & 357 & 181 \\
\hline Median (IQR) & $7.45(7.37-7.48)$ & $7.45(7.38-7.48)$ & $7.42(7.34-7.48)$ \\
\hline \multicolumn{4}{|l|}{ Creatinine } \\
\hline Number of patients & 529 & 353 & 176 \\
\hline Median (IQR), mg/dL & $0.8(0.7-1.0)$ & $0.8(0.6-0.9)$ & $0.9(0.7-1.2)$ \\
\hline \multicolumn{4}{|l|}{ Bilirubin } \\
\hline Number of patients & 502 & 332 & 170 \\
\hline Median (IQR), mg/dL & $0.5(0.4-0.6)$ & $0.5(0.4-0.6)$ & $0.5(0.4-0.7)$ \\
\hline \multicolumn{4}{|l|}{ SAPS 3} \\
\hline Number of patients & 575 & 385 & 190 \\
\hline Median (IQR) & $53(46-60)$ & $51(45-56)$ & $59(52-64)$ \\
\hline \multicolumn{4}{|l|}{ Predicted risk of death } \\
\hline Number of patients & 575 & 385 & 190 \\
\hline Median (IQR) & $22 \%(12-36 \%)$ & $19 \%(11-28 \%)$ & $34 \%(20-44 \%)$ \\
\hline
\end{tabular}

$\mathrm{COPD}=$ chronic obstructive pulmonary disease; $\mathrm{FiO}_{2}=$ fraction of inspired oxygen; $\mathrm{ICU}=$ intensive care unit; $\mathrm{IQR}=$ interquartile range; $\mathrm{PaO}_{2}=$ arterial partial pressure of oxygen; SAPS = Simplified Acute Physiology Score. * Morbid obesity was defined as a body mass index above $40 \mathrm{~kg} / \mathrm{m}^{2}$. + Malignancy is defined as neoplasia spread beyond regional lymph nodes. \# Body temperature above $38^{\circ} \mathrm{C}$.
Compared with patients without comorbidities, crude mortality was markedly higher among patients with one or more comorbidities, with the highest mortality rate observed among patients with liver disease, neuromuscular disease, and malignancy (Figure 3). Time to death is shown in Figure 4. On univariable Cox regression analysis, age, the presence of one or more comorbidities, COPD or asthma, hypertension, SAPS 3, and hospital level were associated with 30-day mortality. On multivariable Cox regression analysis, age (hazard ratio [HR], 1.06; 95\% Cl, 1.04-1.07 per year) and the presence of one or more comorbidities ( $\mathrm{HR}$, $1.80 ; 95 \% \mathrm{Cl}, 1.20-2.68)$ were associated with 30-day mortality after adjustment for acute illness severity at admission (SAPS 3 excluding age and comorbidity components), and hospital level (Table 3). When assessing specific comorbidities in the multivariable model, COPD or asthma (HR, 1.68; $95 \% \mathrm{Cl}$, 1.12-2.50) and hypertension (HR, 1.41; $95 \% \mathrm{Cl}, 1.01-$ 1.99) remained significantly associated with mortality (Table 4).

\section{Discussion}

We conducted a populationbased study of all patients with COVID-19 admitted to an ICU in Sweden until 5 April 2020. Among 604 patients with complete follow-up, of whom $85 \%$ received invasive 


\begin{tabular}{|c|c|c|c|}
\hline Variable & All patients & Survivors & Non-survivors \\
\hline Total number of patients & 604 & 407 & 197 \\
\hline $\begin{array}{l}\text { Highest level of respiratory support } \\
\text { (number of patients with data) }\end{array}$ & 573 & 384 & 189 \\
\hline Invasive mechanical ventilation & $487(85.0 \%)$ & $315(82.0 \%)$ & $172(91.0 \%)$ \\
\hline $\begin{array}{l}\text { Non-invasive mechanical } \\
\text { ventilation }\end{array}$ & $16(2.8 \%)$ & $10(2.6 \%)$ & $6(3.2 \%)$ \\
\hline \multicolumn{4}{|l|}{$\begin{array}{l}\text { Duration of invasive mechanical } \\
\text { ventilation (hours) }\end{array}$} \\
\hline Number & 481 & 310 & 171 \\
\hline Median (IQR) & $282(177-444)$ & $305(202-503)$ & $230(112-389)$ \\
\hline Renal replacement therapy & $117 / 518(22.6 \%)$ & $67 / 342(19.6 \%)$ & $50 / 176(28.4 \%)$ \\
\hline Prone position & $182 / 508(35.8 \%)$ & 108/334 (32.3\%) & $74 / 174(42.5 \%)$ \\
\hline $\mathrm{ECMO}$ & $3 / 372(0.8 \%)$ & $2 / 240(0.8 \%)$ & $1 / 132(0.8 \%)$ \\
\hline Tracheostomy & $136 / 567(24.0 \%)$ & $111 / 379(29.3 \%)$ & $25 / 188(13.3 \%)$ \\
\hline Chloroquine phosphate use & $304 / 604(50.3 \%)$ & 207/407 (50.9\%) & 97/197 (49.2\%) \\
\hline \multicolumn{4}{|l|}{ ICU length of stay (days) } \\
\hline Number & 571 & 381 & 190 \\
\hline
\end{tabular}

$\mathrm{ECMO}=$ extracorporeal membrane oxygenation; ICU = intensive care unit; IQR = interquartile range. mortality, independent of the degree of acute illness severity on admission.

While most countries share the same goal of ensuring and controlling health care and limit the economic consequences of the COVID-19 pandemic, Sweden has taken a different route to reach these common goals. In contrast to political and governmental reinforcement of country- or region-wide lockdowns, sweden has built its strategy on a combination of binding regulations and nonpolitical nationwide voluntary restrictions and quarantine recommendations including social distancing.

To date, few studies have assessed mortality beyond ICU discharge among critically ill patients with COVID-19. Data from single-centre studies report a 28-day mortality between $39 \%$ and $62 \% .8,13$ A different age and comorbidity distribution may explain the somewhat lower mortality observed in our cohort. Indeed, our patients were slightly younger, and a lower proportion had chronic illness than reported in ICU cohorts with higher mortality rates. 1,3,6 However, we observed a mortality of almost $80 \%$ in patients aged 80 years or older in agreement with previously published data. ${ }^{1}$ In a recently published review and meta-analysis of ICU mortality for patients with COVID-19, in patients with completed ICU admissions, the combined ICU mortality was $41.6 \%$. However, mechanical ventilation and $23 \%$ were treated with renal replacement therapy, we observed an overall mortality within 30 days of $33 \%$. In adjusted analyses, age, COPD or asthma, chronic hypertension and the presence of one or more comorbidities were associated with higher 30-day there was high heterogeneity of reported outcomes, suggesting that survival rates between studies are highly variable. In addition, data from many countries are lacking. ${ }^{17}$

Hypertension and diabetes were the most common comorbidities, as previously reported in critically ill patients 
Figure 3. 30-day mortality in different comorbidity groups

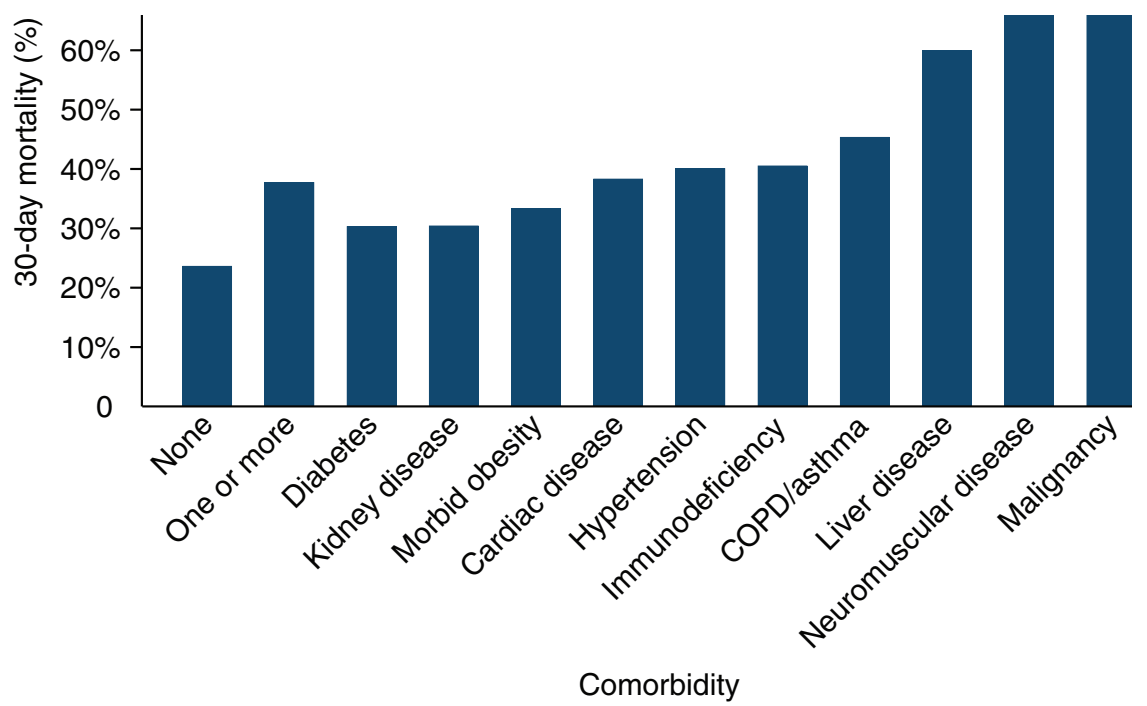

$\mathrm{COPD}=$ chronic obstructive pulmonary disease.

Figure 4. Probability of survival at 30 days $-579 / 604$ study patients $(95.8 \%)$ had available information on date of death

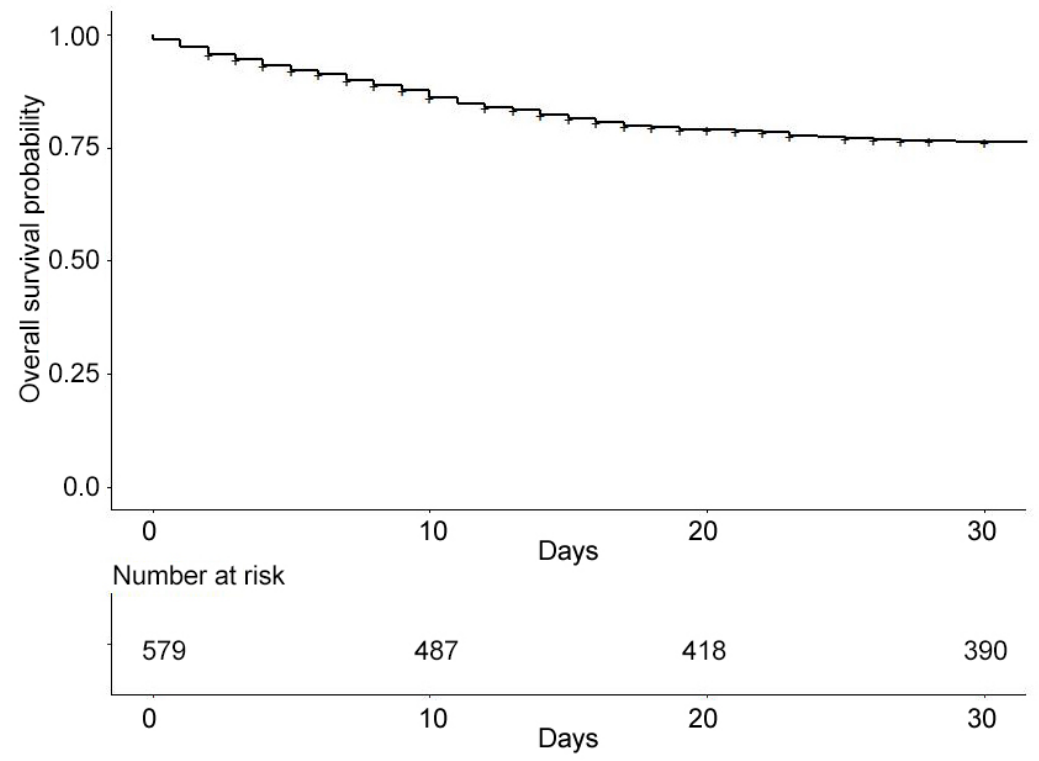

COPD = chronic obstructive pulmonary disease with COVID-19.1,3,13 In addition to patient characteristics, acute illness severity will have a major impact on survival. In the current study, $85 \%$ of patients with COVID-19 required invasive mechanical ventilation and $23 \%$ received renal replacement therapy, broadly reflecting the degree of illness severity and treatment intensity in previous reports.

We found that the presence of one or more comorbidities was associated with 30-day mortality after adjustment for age and illness severity at admission. Previously published data on age-adjusted associations between the burden of comorbidities and mortality in patients with COVID-19 admitted to hospital are inconsistent. Differences in covariate definitions could contribute to this in addition to varying length of follow-up. Liang and colleagues $^{18}$ assessed several risk factors in a large cohort of 1590 patients with COVID-19 admitted to hospital. They found that the number of chronic illnesses was independently associated with the composite outcome of ICU admission or invasive ventilation or death. Similar to our results, Zangrillo et al ${ }^{11}$ reported that hypertension was associated with early mortality among 73 mechanically ventilated patients. However, Wu and colleagues $^{19}$ found no crude associations between hypertension or diabetes and mortality in 84 patients with COVID-19 acute respiratory distress syndrome. Moreover, in a cohort of 191 patients admitted to two hospitals in Wuhan, China, the presence of COPD, coronary heart disease, diabetes or hypertension was not associated with in-hospital death after adjustment for age and Sequential Organ Failure Assessment (SOFA) score. ${ }^{20}$ We found an independent association of COPD or asthma and hypertension with death. To the best of our knowledge, our study is the first population-based study 


\section{ORIGINAL ARTICLES}

Table 3. Univariate and multivariable Cox regression analysis for 30-day mortality

\begin{tabular}{|c|c|c|c|c|}
\hline & \multicolumn{2}{|c|}{ Univariate } & \multicolumn{2}{|c|}{ Multivariable* } \\
\hline & $\begin{array}{c}\text { Hazard ratio } \\
(95 \% \mathrm{Cl})\end{array}$ & $P$ & $\begin{array}{c}\text { Hazard ratio } \\
(95 \% \mathrm{Cl})\end{array}$ & $P$ \\
\hline \multicolumn{5}{|l|}{ Sex } \\
\hline Female & Reference & & Reference & \\
\hline Male & $1.13(0.76-1.69)$ & 0.54 & & \\
\hline Age $\left(\right.$ per year) ${ }^{\dagger}$ & $1.06(1.05-1.08)$ & $<0.001$ & $1.06(1.04-1.07)$ & $<0.001$ \\
\hline \multicolumn{5}{|l|}{ Comorbidity } \\
\hline None & Reference & & Reference & \\
\hline One or more & $2.23(1.50-3.31)$ & $<0.001$ & $1.80(1.20-2.68)$ & 0.004 \\
\hline $\begin{array}{l}\text { SAPS } 3 \text { (per } 1 \text { unit } \\
\text { increase) })^{\ddagger}\end{array}$ & $1.07(1.05-1.09)$ & $<0.001$ & $1.06(1.04-1.09)$ & $<0.001$ \\
\hline \multicolumn{5}{|l|}{ Hospital level } \\
\hline Tertiary & Reference & & & \\
\hline County & $1.73(1.18-2.54)$ & 0.005 & $1.44(0.97-2.13)$ & 0.07 \\
\hline Local & 1.59 (0.84-2.99) & 0.15 & $1.23(0.65-2.32)$ & 0.53 \\
\hline
\end{tabular}

SAPS = Simplified Acute Physiology Score. * 574 patients included in the multivariable model. Concordance: 0.745 . † The hazard ratio indicates the change in the risk of death per one year increase in age. \# SAPS 3 was recalculated after removing age and comorbidity components.

Table 4. Univariate and multivariable Cox regression analysis for 30-day mortality

\begin{tabular}{|c|c|c|c|c|}
\hline & \multicolumn{2}{|c|}{ Univariate } & \multicolumn{2}{|c|}{ Multivariable* } \\
\hline & $\begin{array}{c}\text { Hazard ratio } \\
(95 \% \mathrm{Cl})\end{array}$ & $P$ & $\begin{array}{c}\text { Hazard ratio } \\
(95 \% \mathrm{Cl})\end{array}$ & $P$ \\
\hline \multicolumn{5}{|l|}{ Sex } \\
\hline Female & Reference & & Reference & \\
\hline Male & $1.13(0.76-1.69)$ & 0.54 & & \\
\hline Age $(\text { per year })^{+}$ & $1.06(1.05-1.08)$ & $<0.001$ & $1.06(1.04-1.08)$ & $<0.001$ \\
\hline \multicolumn{5}{|l|}{ Comorbidity } \\
\hline Cardiac disease & $1.33(0.79-2.24)$ & 0.28 & & \\
\hline COPD or asthma & $1.80(1.21-2.67)$ & 0.004 & $1.68(1.12-2.50)$ & 0.01 \\
\hline Diabetes & $0.94(0.64-1.39)$ & 0.77 & & \\
\hline Morbid obesity & $1.33(0.74-2.41)$ & 0.34 & & \\
\hline Hypertension & $1.82(1.30-2.54)$ & $<0.001$ & $1.41(1.01-1.99)$ & 0.046 \\
\hline SAPS 3 (per 1 unit increase) $)^{\ddagger}$ & $1.07(1.05-1.09)$ & $<0.001$ & $1.07(1.05-1.09)$ & $<0.001$ \\
\hline \multicolumn{5}{|l|}{ Hospital level } \\
\hline Tertiary & Reference & & & \\
\hline County & $1.73(1.18-2.54)$ & 0.005 & $1.44(0.97-2.12)$ & 0.07 \\
\hline Local & $1.59(0.84-2.98)$ & 0.15 & $1.27(0.67-2.40)$ & 0.47 \\
\hline
\end{tabular}

COPD $=$ chronic obstructive pulmonary disease SAPS = Simplified Acute Physiology Score. ${ }^{*} 574$ patients included in the multivariable model. Concordance: 0.739 . + The hazard ratio indicates the change in the risk of death per one year increase in age. ₹ SAPS 3 was recalculated after removing age and comorbidity components. of ICU patients with sufficient power to assess associations between comorbidities and 30day mortality, independent of age and acute illness severity. We were unable to fully elucidate the impact of chronic liver disease, chronic kidney disease, neuromuscular disease and malignancy (metastases beyond regional lymph nodes) due to limited number of such comorbidities in our cohort.

Our study has several strengths. First, we analysed a large, nationwide multicentre cohort of ICU patients with COVID-19 with respect to 30 -day mortality, thus providing a high degree of external validity and generalisability to comparable populations. Second, variables were prospectively collected for quality surveillance purposes and are therefore likely to be unbiased. Third, data underwent a two-step validation process (at each participating ICU before submission to the registry and centrally before data extraction), assuring a high level of internal validity. Complete follow-up was ascertained by linkage between SIR and national registries. Finally, very few patients were still in the ICU at study end point, which differs from previously published reports on ICU patients with COVID-19.1,6,8 Our study has limitations associated with the registrybased study design. Information on socio-economic status or ethnicity was not available. Furthermore, the severity of reported comorbidities, chronic medication, and potentially beneficial treatment during ICU stay, such as low molecular weight heparin, are not registered in SIR. Data on 


\section{ORIGINAL ARTICLES}

patients not admitted to an ICU were not available in the current study, possibly limiting interpretation of mortality figures. Functional outcomes and long term outcomes were not included. Finally, data on ICU staffing during the study period were unavailable.

\section{Conclusion}

In conclusion, in this population-based cohort of 604 ICU patients with COVID-19, one-third died within 30 days. Older age, the presence of one or more comorbidities, COPD or asthma, chronic hypertension and the degree of acute illness severity at admission were associated with 30day mortality.

Acknowledgements: We thank the participating ICUs for their hard work in contributing data to the Swedish Intensive Care Registry.

\section{Competing interests}

None declared.

\section{Funding}

The study received sponsorship from the Knut and Alice Wallenberg Foundation.

\section{Author details}

Johan Mårtensson*,1,2

Lars Engerström*,3,4,5

Sten Walther $r^{3,4,5}$

Jonathan Grip ${ }^{2,6}$

Ritva Kiiski Berggren ${ }^{5,7}$

Emma Larsson ${ }^{1,2,5}$

* Equal first authors.

1 Department of Physiology and Pharmacology, Karolinska Institutet, Stockholm, Sweden.

2 Department of Perioperative Medicine and Intensive Care, Karolinska University Hospital, Stockholm, Sweden.

3 Department of Cardiothoracic Surgery, Anesthesia and Intensive Care; Linköping University Hospital, Linköping, Sweden.

4 Department of Medical and Health Sciences, Linköping University, Linköping, Sweden.

5 The Swedish Intensive Care Registry, Karlstad, Sweden.

6 Department of Clinical Science, Intervention and Technology (CLINTEC), Karolinska Institutet, Stockholm, Sweden.

7 Department of Anesthesia, Intensive Care and Perioperative Services, Umeå University Hospital, Umeå, Sweden.

Correspondence: johan.martensson@sll.se

\section{References}

1 Grasselli G, Zangrillo A, Zanella A, et al. Baseline characteristics and outcomes of 1591 patients infected with SARS-CoV-2 Admitted to ICUs of the Lombardy Region, Italy. JAMA 2020; 323: 1574-81.

2 Guan WJ, Ni ZY, Hu Y, et al. Clinical characteristics of coronavirus disease 2019 in China. N Engl J Med 2020; 382: 1708-20.

3 Myers LC, Parodi SM, Escobar GJ, Liu VX. Characteristics of hospitalized adults with COVID-19 in an integrated health care system in California. JAMA 2020; 323: 2195-8.

4 Young BE, Ong SWX, Kalimuddin S, et al. Epidemiologic features and clinical course of patients infected with SARSCoV-2 in Singapore. JAMA 2020; 323: 1488-94.

5 Salje H, Tran Kiem C, Lefrancq N, et al. Estimating the burden of SARS-CoV-2 in France. Science 2020; 369: 208-11.

6 Arentz M, Yim E, Klaff L, et al. Characteristics and outcomes of 21 critically ill patients with COVID-19 in Washington State. JAMA 2020; 323: 1612-4.

7 Richardson S, Hirsch JS, Narasimhan M, et al. Presenting characteristics, comorbidities, and outcomes among 5700 patients hospitalized with COVID-19 in the New York City area. JAMA 2020; 323: 2052-9.

8 Yang $X, Y u Y, X u$ J, et al. Clinical course and outcomes of critically ill patients with SARS-CoV-2 pneumonia in Wuhan, China: a single-centered, retrospective, observational study. Lancet Respir Med 2020; 8: 475-81.

9 Novel Coronavirus Pneumonia Emergency Response Epidemiology Team. Vital surveillances: the epidemiological characteristics of an outbreak of 2019 novel coronavirus diseases (COVID-19) - China, 2020. China CDC Weekly 2020; 8: 113-22. http://weekly.chinacdc.cn/en/article/id/e53946e2c6c4-41e9-9a9b-fea8db1a8f51 (viewed Sept 2020).

10 Auld SC, Caridi-Scheible M, Blum JM, et al. ICU and ventilator mortality among critically ill adults with coronavirus disease 2019. Crit Care Med 2020; doi: 10.1097/ CCM.0000000000004457 [Epub ahead of print].

11 Zangrillo A, Beretta L, Scandroglio AM, et al. Characteristics, treatment, outcomes and cause of death of invasively ventilated patients with COVID-19 ARDS in Milan, Italy. Crit Care Resusc 2020; 22: 200-11.

12 Wang K, Zhang Z, Yu M, et al. 15-day mortality and associated risk factors for hospitalized patients with COVID-19 in Wuhan, China: an ambispective observational cohort study. Intensive Care Med 2020; 46: 1472-4.

13 Wang Y, Lu X, Li Y, et al. Clinical course and outcomes of 344 intensive care patients with COVID-19. Am J Respir Crit Care Med 2020; 201: 1430-4.

14 Swedish National Quality Registries. http://www. kvalitetsregister.se/englishpages.2040.html (viewed Aug 2020).

15 Public Health Agency of Sweden. [Number of COVID-19 cases in Sweden (website)]. [Swedish] https://experience.arcgis. 


\section{ORIGINAL ARTICLES}

com/experience/09f821667ce64bf7be6f9f87457ed9aa (viewed Aug 2020).

16 National Board of Health and Welfare. [Statistics on inpatient care for patients with COVID-19 (website)]. [Swedish] https:// www.socialstyrelsen.se/statistik-och-data/statistik/statistikom-covid-19/statistik-om-slutenvard-av-patienter-medcovid-19/ (viewed Aug 2020).

17 Armstrong RA, Kane AD, Cook TM. Outcomes from intensive care in patients with COVID-19: a systematic review and meta-analysis of observational studies. Anaesthesia 2020; doi: 10.1111/anae.15201 [Epub ahead of print].
18 Liang $\mathrm{W}$, Liang $\mathrm{H}$, Ou $\mathrm{L}$, et al. Development and validation of a clinical risk score to predict the occurrence of critical illness in hospitalized patients with COVID-19. JAMA Intern Med 2020; 180: 1-9.

19 Wu C, Chen X, Cai Y, et al. Risk factors associated with acute respiratory distress syndrome and death in patients with coronavirus disease 2019 pneumonia in Wuhan, China. JAMA Intern Med 2020; 180: 1-11.

20 Zhou F, Yu T, Du R, et al. Clinical course and risk factors for mortality of adult inpatients with COVID-19 in Wuhan, China: a retrospective cohort study. Lancet 2020; 395: 1054-62. 